\title{
FORMAÇÃO DOS PROFISSIONAIS DA CIDADE DE SOCORRO- SP EM ATIVIDADES DE AVENTURA NO ÂMBITO DO LAZER
}

\author{
Recebido em: 08/12/2015
}

Aceito em: 12/10/2016

José Ricardo Auricchio

Universidade Metodista de Piracicaba

Piracicaba - SP - Brasil

\begin{abstract}
RESUMO: As atividades de aventura são consideradas uma das vertentes do lazer, presentes muitas vezes nos conteúdos turísticos e físico-esportivos que levam o praticante a sensações de vertigem, adrenalina e perda momentânea de autocontrole. Dentre os profissionais que atuam com as atividades de aventura estão professores de Educação Física, turismólogos, animadores socioculturais, recreadores entre outros. Porém, nos intriga a questão: Qual a formação técnica em termos de conteúdo específico e no âmbito dos estudos do lazer os profissionais que atuam com atividades de aventura possuem para trabalhar na área? O objetivo deste trabalho foi caracterizar a formação profissional dos instrutores de atividades de aventura na cidade de Socorro. Como procedimento metodológico foram utilizadas a pesquisa bibliográfica com consulta as bibliotecas da USP, UNICAMP e UNIMEP e no banco de teses da CAPES, nos últimos cinco anos, sobre as palavras-chave "atividades de aventura", "lazer" e "formação profissional" e também a pesquisa de campo com aplicação de questionário semiestruturado com questões abertas e fechadas aos profissionais que lidam diretamente com o público. Os profissionais que trabalham com atividades de aventura na cidade de Socorro têm em sua maioria formação universitária nos mais variados cursos e/ou formação técnica na atividade que exerce, demonstrando que a formação universitária é desejável, porém não é imprescindível para se trabalhar na área. Somado a isso, o curso de Educação Física, como formação superior, foi o mais citado entre os participantes da pesquisa.
\end{abstract}

PALAVRAS CHAVE: Atividades de Lazer. Desenvolvimento de Pessoal. Educação Física e Treinamento.

\section{TRAINING OF THE ADVENTURE ACTIVITIES PROFESSIONALS ON THE LEISURE CONTEXT IN SOCORRO-SP CITY}

ABSTRACT: Adventure activities are considered as leisure option, in tourist and physical-sport contents that lead the practitioner to vertigo sensations, adrenaline and self-control loss momentary. The adventure activities professionals are Physical Education teachers, tour guide, sociocultural animators, recreators and others. However, what is the technical background or specific content in leisure studies, adventure activities professionals have to work in this area? The aim of this study was to characterize the training of adventure activities professionals in Socorro city. The 
methodological procedure was bibliographical research in libraries USP, Unicamp and UNIMEP and CAPES thesis database. Was consider the last five years and the keywords "adventure activities", "leisure" and "training professional". The field research was used semi-structured questionnaire with open and closed questions. Adventure activities professionals in Socorro have university training in several courses and/or technical training in activity that works. In this sense, university training is desirable, but not essential to work in this area. In additional this, the Physical Education course, as training in higher education, was the most cited among the participants in this study.

KEYWORDS: Leisure Activities. Staff Development. Physical Education and Training.

\section{Introdução}

Mesmo em pleno século 21, aventura e perigo ainda são atividades inerentes a própria evolução humana. Atividades estas que podem conter risco, e este risco pode ser considerado como um conjunto de atividades que envolvem desafios consideráveis, tornando-se motivador para que mais pessoas busquem tais práticas que se tornaram contemporâneas (SPINK; SPINK, 2009).

Com o crescimento das práticas corporais de aventura como esportes ou turismo, o número de pessoas contratadas para trabalhar com as atividades de aventura em empresas, hotéis e acampamentos tem apresentado significativo aumento, nas últimas décadas.

Alguns desses profissionais ${ }^{1}$ estão se especializando em cursos de formação específica ou buscando uma formação desejável, porém não imprescindível (PINA, 1995), em cursos superiores de Turismo ou Educação Física, nas quais foram inseridas algumas disciplinas relacionadas as práticas de aventura nos últimos anos. Como alternativa aos que possuem cursos de graduação em outras áreas, há cursos de extensão

\footnotetext{
${ }^{1}$ Designamos por "profissionais" as pessoas que trabalham com atividades de aventura com contato direto com o público.
} 
e especialização em esportes e atividades de aventura, promovidos por universidades da região Sul e Sudeste do Brasil.

As atividades de aventura são consideradas uma vertente da área de lazer e isso faz com que esses profissionais deixem de ser meros acompanhantes e passem a intervir de forma construtiva e responsável nestas atividades (FREIRE, 2006).

Terezani (2010) relata que em razão da proliferação das atividades de aventura, torna-se fundamental compreendermos os conteúdos referentes ao lazer, as principais características do ambiente lúdico, e ainda estabelecermos a relação entre os animadores socioculturais $^{2}$ e as práticas corporais que promovem a radicalidade.

A formação profissional em atividades de aventura é um tema instigante e inovador no campo dos estudos do lazer, sobretudo hoje, quando há um mercado voltado para as atividades de aventura, tornando cada vez mais necessária uma formação que se proponha a lidar com as características deste setor. Portanto, este estudo faz-se importante para o conhecimento sobre a formação técnica específica destes profissionais, bem como, se estão de acordo com as normas apresentadas e qual a necessidade dessa formação no âmbito do lazer, dos instrutores e monitores de atividades de aventura.

O objetivo deste trabalho foi caracterizar a formação profissional dos instrutores de atividades de aventura na cidade de Socorro, interior do Estado de São Paulo. Observando a formação técnica e a formação relacionada aos estudos do lazer, especificamente o lazer na natureza ou outdoor recreation ${ }^{3}$, bem como a formação profissional pertinente para este profissional.

\footnotetext{
${ }^{2}$ Termo sugerido por Dumazedier, para o corpo de profissionais que trabalham na intervenção sobre o lazer (2001, p. 50).

${ }^{3}$ Termo citado por Parker (1978).
} 


\section{Desenvolvimento}

Para um melhor entendimento do texto, começaremos com uma breve conceituação dos termos que foram desenvolvidos como lazer, atividade de aventura e formação profissional.

Em seu sentido original, a palavra grega schole era "parar" ou "cessar" e, portanto, ter paz e silêncio. Posteriormente, passou a significar tempo disponível ou especialmente, “tempo para si”. O lazer é uma condição ou estado - o estado de estar livre da necessidade de trabalho (PARKER, 1978, p. 26).

Colocamos a seguir a definição de lazer proposta por Dumazedier e Marcellino, respectivamente:

[...] conjunto de ocupações às quais o indivíduo pode entregar-se de livre vontade, seja para repousar, seja para divertir-se, recrear-se e entreter-se ou ainda para desenvolver sua formação desinteressada, sua participação social voluntária, ou sua livre capacidade criadora, após livrar-se ou desembaraçar-se das obrigações profissionais, familiares e sociais (DUMAZEDIER, 2001, p.34).

Manifestação humana em que a opção pela atividade possui estreita relação com as demais áreas de atuação do ser humano, caracterizado pelos aspectos tempo e atitude, vivenciados no 'tempo disponível' das obrigações profissionais, familiares, sociais e religiosas, um fenômeno gerado historicamente e do qual emergem valores questionadores da sociedade como um todo, e sobre o qual são exercidas influências da estrutura social vigente (MARCELLINO, 1995, p. 31-2).

Parker (1978 p.48) cita ainda as funções do lazer propostas por Meyershon, sendo que a terceira função encaixa-se perfeitamente nas atividades de aventura: "Entretanto, os valores dominantes em nossa sociedade nos encorajam a buscar êxitos em todas as esferas da vida e a ser competentes no que fazemos - lazer como realização própria".

Podemos citar também os aspectos educativos do lazer, considerado “[...] veículo e objeto de educação" (MARCELLINO, 1995, p. 36), em virtude das 
semelhanças entre as atividades que envolvem o lazer e as atividades de aventura. Dessa forma, segundo Correa (2008), o ser humano, além de se divertir com atividades no âmbito do lazer no meio natural, pode, também, adquirir conhecimentos sobre a natureza e seus componentes (por exemplo, fauna e flora), tendo uma visão crítica e criativa do que está vivenciando.

Entretanto, quanto à atuação, os animadores socioculturais, trabalhadores das mais diversas áreas do lazer, devem apresentar uma dupla qualificação, exercendo sua competência, bem como sua consciência social, em pelo menos um setor cultural. Isto se torna relevante, uma vez que a maioria das pessoas tende a direcionar suas atividades de lazer a um campo restrito de interesse, geralmente por não vivenciar ou não conhecer outros interesses culturais (MARCELLINO, 1983).

Ainda em relação a atuação desses profissionais, Stoppa et al. (2010) nos trazem que:

\begin{abstract}
Os profissionais que atuam no campo do lazer podem exercer diversas funções e cada um possui uma especificidade envolvendo uma diversidade de domínios, fundamentos, competências e habilidades. Em virtude dessa multiplicidade de funções que podem ser exercidas pelo profissional, várias são suas denominações: monitor, recreador, consultor de lazer, gentil organizador, agente cultural, militante cultural, animador. Para o profissional, essa diversidade de funções e denominações, em conjunto com uma visão parcial da dimensão do lazer, ou seja, uma limitação do seu entendimento, não permitindo que ele o entenda como manifestação humana experimentada ou assistida no tempo disponível, corrobora para que sua ação nas diversas áreas existentes nesse setor seja limitada (p.05).
\end{abstract}

Alguns autores, como Betrán (2003); Ferreira (1989); Uvinha (2001, 2005a); Buckley e Uvinha (2011); Marinho e Schwartz (2005) e Dias (2009) nos trazem como terminologias as palavras esportes radicais, turismo de aventura e atividades físicas de aventura na natureza. Encontramos ainda na literatura as definições propostas tanto pelo 
ministério do turismo quanto pelo ministério do esporte. Utilizaremos o termo atividades de aventura de acordo com Pimentel (2013 p. 698):

[...] mais que um vocábulo 'guarda-chuva', atividades de aventura (apesar das críticas que o termo 'atividade' recebe na Educação Física) pode apenas tratar-se de uma solução provisória para uma comunidade que carece de discussão acumulada para alçar novos patamares conceituais.

O termo que permeia as definições no nosso entender é atividades de aventura, sob uma visão própria do lazer, e não como sub conteúdo do lazer físico-esportivo (MARCELLINO, 2002) ou outro. Reforçando nossa posição, o termo "atividades de aventura" é utilizado nos congressos da área: Congresso Brasileiro de Atividades de Aventura e Congresso Internacional de Atividades de Aventura.

Em um entendimento mais aprofundado, Buckley e Uvinha (2011 p.7) trazemnos definições da palavra "aventura" utilizada por dicionários de diferentes países como: "experiência inesperada ou emocionante", "iniciativa ousada", "atividade perigosa", "uma experiência emocionante", "um ato de resultado incerto, uma iniciativa arriscada", "o encontro com riscos", "uma realização ousada na qual há riscos e que conta com eventos imprevistos". Todas estas definições, portanto, incluem elementos de emoção, incerteza e perigo.

Nas atividades de aventura e no lazer a formação profissional é de extrema importância e não se trata apenas de estudos isolados, pois essa formação deve ser multidisciplinar (ISAYAMA, 2010), e deve priorizar a formação inicial que é a base de todo o processo (WERNECK, 2000).

As atividades de aventura na natureza, mais especificamente, vêm conquistando mais espaços, como campo de reflexões e intervenções, exigindo um novo perfil de profissional que, reitere a validade dessa proposta como uma estratégia criativa, crítica e 
lúdica, facilitadora do reencontro dos seres humanos com a natureza. Dessa forma, aponta-se para a necessidade da existência de uma pedagogia capaz de incorporar aspectos lúdicos, potencializados por meio de uma educação para o lazer e a recreação (MARINHO; DE GÁSPARI, 2003)

Uvinha (2009), ressalta o momento atual que a área denominada como Turismo de Aventura, no mundo todo, em relação há necessidade de uma certificação para operações comerciais, o que no Brasil começou em 2004, mas que segundo o autor, acontece desde a década de 1980 em outras regiões do mundo.

Algumas entidades do turismo, como a Associação Brasileira das Empresas de Ecoturismo e Turismo de Aventura (ABETA) e o Ministério do Turismo (MTUR), junto com a Associação Brasileira de Normas Técnicas (ABNT), publicaram normas técnicas para algumas atividades, como montanhismo, mergulho, caminhada, espeleoturismo, entre outras, com foco no que o monitor (condutor) deve seguir em sua formação. Estas normas estão em vigor desde 2005 e as empresas vêm, desde então, se adequando para cumpri-las (ABETA, 2005; BRASIL, 2005).

Algumas normas foram revisadas no ano de 2014 para atenderem as normativas da certificação ISO, com isso tivemos a republicação dessas normas com tais adequações.

Como o próprio nome já diz, são normas técnicas de conteúdo específicos para cada modalidade, não levando em consideração outros conteúdos presentes nas atividades de aventura, como o lazer, a educação ambiental, etc.

Trataremos, então, da formação profissional utilizando estudos sobre as competências necessárias no âmbito do lazer, área em que, desde a década de 1990 e meados de 2000, Marcellino (2000) vem questionando a formação do profissional que 
nela atua. Este texto não visa responder a tais questionamentos, que são ainda atuais, mas sua discussão principal basear-se-á neles.

Para Mello (2010) e Marcellino (1995) o profissional que irá trabalhar com lazer deve ter uma sólida formação relacionada a conteúdos culturais e possa fazer a intersecção entre as problemáticas do lazer e as demais dimensões da ação humana, em um exercício constante de reflexão.

Para Stoppa é importante salientar que a formação dos profisssionais que atuam em locais que desenvolvem atividades de lazer relacionadas aos diferentes conteúdos deve estar sempre em constante transformação, de acordo com seu papel de educador que é construir uma política de lazer que "[...] efetivamente democratize e socialize os bens culturais da humanidade, independentemente de classe social, raça e religião; tendo como princípios básicos a cultura e uma vigilante reflexão do dilema do lazer como mercadoria, produto da indústria cultural" (MAIA, $2003^{4}$, p. 99 apud STOPPA et al., 2010)

Para Marcellino (2007) quando falamos da formação dos profissionais do lazer, podemos distinguir seis categorias possíveis: cursos livres de curta duração, formação de nível superior específica, inserção de habilitações em cursos de nível superior, pósgraduação stricto sensu diversificado com linhas de pesquisa específicas, pós-graduação lato sensu e MBA.

Em relação às atividades de aventura, incluiríamos nas categorias propostas por Marcellino os cursos técnicos específicos de cada modalidade, assim como surgem os

\footnotetext{
${ }^{4}$ MAIA, L. F. S. A formação de técnico em lazer e suas possibilidades de atuação e intervenção em políticas públicas. In: MARCELLINO, N. C. (Org.). Formação e desenvolvimento de pessoal em lazer e esporte. Campinas: Papirus, 2003
} 
cursos técnicos em lazer, como o mesmo autor cita ao falar sobre a formação para a área do lazer:

\begin{abstract}
Os processos de formação de profissionais para atuação na área do lazer vêm ganhando cada vez mais espaço no Brasil, em decorrência da demanda verificada no mercado, em franca expansão. Além da inclusão de disciplinas específicas em cursos de graduação, como educação física, turismo, hotelaria entre outros, já começam a surgir os primeiros cursos específicos de graduação e um número razoável de cursos técnicos (MARCELLINO, 2003 p. 9).
\end{abstract}

Na formação profissional no lazer deve haver um vínculo entre a universidade e os demais espaços sociais que compõem nossa realidade e cultura, de modo que o acesso à reflexão teórico-prática e aos saberes científicos, tecnológicos e/ou jurídicos construídos pela humanidade possa atingir seu propósito, que é desenvolver nossa capacidade de orientação em relação a diferentes objetivos e a problemas interdisciplinares, complexos e variados (WERNECK, 1998).

O profissional do lazer, denominado animador sociocultural - termo proposto por Dumazedier, como visto anteriormente -, tem diferentes formações, e isso é extremamente necessário, pela própria abrangência da área cultural. São professores de educação física, arte-educadores, profissionais de turismo, de hotelaria entre outros, que dominam o conteúdo cultural; Têm vontade de dividir esse domínio com outras pessoas, devendo, para isso, possuir uma sólida cultura geral que lhes dê a possibilidade de perceber a intersecção/ligação de seu conteúdo de domínio com os demais; Exercer cotidianamente a reflexão e a valoração próprias da ação do educador, o que os diferenciará dos "mercadores" da grande maioria da indústria cultural e ter o compromisso político com a mudança da situação em que nos encontramos, atuando com base nessa perspectiva (MARCELLINO, 2003). 
Moesch (2003) nos coloca que deve existir um profissional capaz de orientar as vivências sociais e ambientais em áreas públicas que se tornam turísticas quando organizadas para o acesso de visitantes. Porém, esse profissional não deve ter apenas a competência técnica e específica e sim, ser um sujeito construtor de sensibilidade, de criatividade, de desvelamento, de integração entre o humano, o cultural e o ambiental.

Relacionando as atividades de aventura a esses fatores, Uvinha afirma que:

A educação em ambientes externos ou naturais (outdoor education) tem sido mundialmente defendida como ferramenta pedagógica alternativa, com significativas contribuições ao aprendizado do aluno, na busca de uma sociedade transformadora e engajada com as atuais lutas de preservação e conservação ecológicas (UVINHA, 2009, p. $62)$.

O termo outdoor education é entendido por Zink e Boyes (2006), como a prática de levar os alunos em ambientes naturais para fins educacionais, implicando na vivência principalmente de atividades ao ar livre, mas podendo também serem realizadas em ambientes fechados. Essas atividades podem ser: estudos de educação ambiental, visitas a locais culturais, mas lembrando da essência do aprendizado na natureza através de atividades como acampamentos, caminhadas por trilhas, escaladas, canoagem em rios e lagoas, entre outras atividades.

Para Kunreuther e Ferraz (2012), os cursos de educação ao ar livre na forma experiencial ainda não tem grande público no Brasil. Neste tipo de curso, há experiência educacional contínua, pois alunos e instrutores viajam por áreas naturais e podem ter uma estadia que dure mais do que um pernoite. Tais experiências podem se utilizar de modalidades como o montanhismo, canoagem, cavalgadas, esqui na neve, iatismo, entre outras modalidades de deslocamento pela natureza, metodologia essa muito utilizada em diversos países por entidades como a Outward Bound. 
Para que isso ocorra, no entanto, faz-se necessária uma capacitação dos profissionais envolvidos, que poderão ser alunos graduados, pois para Marinho (2004) o profissional que trabalhará com educação ao ar livre e com as atividades de aventura deve saber as possibilidades que estas atividades oferecem como parte integrante dos conteúdos do ensino já na graduação. Por exemplo, seria interessante entender e explicar, por meio da fisiologia do exercício, quais variáveis fisiológicas interferem em uma caminhada em uma trilha ou em uma corrida de orientação; quais músculos são mais exigidos nas remadas do rafting ou da canoagem por intermédio da eletromiografia, nos estudos relacionados à biomecânica do movimento; como as relações sociais se estabelecem entre escaladores, partindo do embasamento dos estudos do lazer e da recreação e da Sociologia.

Seguindo esta lógica, apresentada aos professores de educação física que trabalham os conteúdos da cultura corporal, sugeridos por Neira e Uvinha (2009), é necessário haver uma formação mais específica em tais atividades para que se possa melhor analisar a proposta de um passeio fora da escola e saber, ao menos, o funcionamento de um sistema de gestão de segurança, como explica Auricchio (2012, 2016), para o gerenciamento de risco adequado e maior segurança dos praticantes.

Recorremos então aos estudos de Auricchio (2009) e Uvinha (2009) que tratam da formação do professor de educação física para trabalhar com atividades de aventura, já que tais atividades envolvem risco de acidentes e, muitas vezes, necessitam de equipamentos especiais que devem ser manuseados por profissionais com treinamento para que se minimize a incidência de erros e acidentes.

Em estudo recente, Bandeira e Ribeiro (2015) nos trazem que muitas vezes os condutores de atividades de aventura de outra cidade no interior do Estado de São 
Paulo, assumiam o risco de levar clientes fora dos padrões de segurança e das normas ABNT e até mesmo participar de atividades que não se sentiam preparados, por pressão dos donos de agências, colocando os clientes em situação e risco iminente.

A temática da gestão de segurança nas atividades de aventura se torna a partir dos anos 2000 item essencial dentro dos estudos das atividades de aventura e esportes radicais, abordada de maneira consciente nos cursos de formação técnica específica, mas superficialmente nas disciplinas nas universidades. Um plano de gestão de segurança é item essencial para cada uma das inúmeras modalidades das atividades de aventura e está contemplada com uma norma específica nas publicações da ABNT sobre o turismo de aventura, já citadas anteriormente (AURICCHIO, 2016).

\section{Metodologia}

Como procedimento metodológico, utilizamos o método exploratório, com pesquisa bibliográfica e pesquisa de campo (SEVERINO, 2010). Este estudo foi aprovado pelo comitê de ética em pesquisa da Universidade Metodista de Piracicaba sob o protocolo $n^{\circ} 93 / 11$.

A pesquisa bibliográfica foi efetuada junto aos sistemas de bibliotecas da UNIMEP, USP, UNICAMP e no banco de teses da Capes nos últimos cinco anos, livros, artigos científicos em bases de dados e pesquisas on-line em anais de congressos nacionais e internacionais de educação física, atividade de aventura, turismo e lazer e pelas palavras-chave "atividades de aventura", "lazer" e "formação profissional". Palavras estas que escolhemos por abrangerem o universo a ser pesquisado. 
Como instrumento de pesquisa foi aplicado questionário semiestruturado com questões abertas e fechadas aos profissionais que trabalham com atividades de aventura e lidam diretamente com o público nos locais propostos.

O ministério do turismo considera alguns polos nacionais no Estado de São Paulo, entre eles o Parque Estadual Turístico do Alto Ribeira, a cidade de Brotas e a cidade de Socorro. Em nosso estudo escolhemos a cidade de Socorro, por não terem estudos sobre a região e pela proximidade com o pesquisador, onde pensamos encontrar a maior parte dos profissionais ligados às atividades de aventura. Socorro é uma cidade turística, referência em atividades de aventura terrestres e no atendimento a pessoas com deficiência, oferecendo atividades como o cascading, rafting, trilhas, arvorismo, tirolesa, entre outras.

Os participantes da pesquisa foram os profissionais instrutores ou monitores que estavam atuando diretamente com o público nas atividades de aventura. Todos os participantes estavam cientes do caráter científico desta pesquisa, que não havia obrigatoriedade de participação e que ela não oferecia qualquer tipo de riscos. A amostra foi composta por 27 profissionais que responderam o questionário em seu local de trabalho.

\section{Análise dos Resultados}

De acordo com os resultados estabelecidos entre os 27 questionários, 18 profissionais representam a modalidade do rafting e 11 de técnicas verticais ${ }^{5}$. O tempo de atuação varia muito, porém, treze instrutores têm mais de cinco anos de experiência e nove tem entre um e cinco anos de experiência. Em relação a formação universitária

\footnotetext{
${ }^{5}$ Alguns profissionais atuam em mais de uma modalidade.
} 
metade das respostas foram favoráveis e a outra metade não considerava importante. Dos 13 que consideravam importante, seis condiram o curso de educação física como formação ideal. Todas as respostas foram favoráveis a importância do curso técnico de formação específica, e em relação às atividades que esse curso deveria conter, 16 respostas disseram ser primeiros socorros/resgate, seguido por rafting com cinco e técnicas verticais também com cinco, sendo as principais atividades da cidade, porém, chamou-nos a atenção atividades como paintball, línguas e fisiologia entre as respostas. Em relação às questões sobre quem poderia ministrar tais cursos, aparecem 17 respostas indicando profissionais da área com experiência e apenas três indicando profissionais da área acadêmica. Outro resultado que nos chamou a atenção foi que em 23 das respostas, eles se consideram profissionais do lazer e 25 consideram as atividades de aventura como conteúdo do lazer. Entre as respostas encontramos 13 que concluíram o ensino médio, nove que concluíram o ensino superior e três com pós-graduação latu senso. Para trabalhar na área, 21 fizeram cursos específicos nas modalidades e dez fizeram também cursos de primeiros socorros e resgate. Todas as respostas foram afirmativas sobre se o profissional de atividade de aventura deva ter conhecimentos específicos além dos técnicos, sendo 17 respostas para os conhecimentos sobre o corpo humano, lazer, educação ambiental e natureza.

Foram consenso, entre os sujeitos da pesquisa, que profissionais experientes ${ }^{6}$ são as pessoas mais capacitadas para ministrar cursos de formação específica para as atividades de aventura. Conforme constatado, este profissional muitas vezes não possui uma formação básica relacionada aos conteúdos por eles mesmos citados, como primeiros socorros e resgate, procedimentos de segurança, didática, psicologia,

\footnotetext{
${ }^{6}$ Profissionais que trabalham há muito tempo com certa atividade e que dominam muito sobre o conhecimento técnico da mesma.
} 
comunicação, lazer, meio ambiente, corpo humano e, até mesmo, educação ambiental. Ele tem consciência de que lhe falta conhecimento, mas entende que não precisa vir da faculdade, mas de outros cursos e os mais confiáveis são os fornecidos pelas associações, federações e confederações.

O professor de educação física aparece em muitas das respostas como pessoa capacitada a ministrar cursos de formação específica na área das atividades de aventura e é considerado pessoa de confiança para esses profissionais. Mas, segundo nossa pesquisa bibliográfica, esse profisssional não tem uma capacitação adequada para isso durante seu curso de licenciatura ou bacharelado e somente com uma especialização na área, como uma pós-graduação em esportes de prancha ou uma pós-graduação em esportes e atividades de aventura, este profissional estará apto a realizar essa intervenção de forma satisfatória no que diz respeito a conteúdos técnicos específicos. Ainda assim, estará longe de obter o conhecimento de um profissional com dez ou vinte anos de experiência na área.

A formação em Educação Física foi a mais indicada em virtude dos conteúdos abordados em sua grade, pois estes podem ser muito aproveitados na atuação na área. Porém, essa formação ainda deve ser complementada por cursos específicos nas modalidades em que se vai atuar e também em modalidades afins para que então se consiga trabalhar de forma a inter-relacionar as atividades e conhecimentos, o que trará um benefício maior para quem atua e para quem prática.

Pina (1995) diz que o profissional do lazer não deve, necessariamente, ser formado em algum curso superior, sendo essa formação é desejável, mas não imprescindível. Ainda no campo da formação profissional do lazer, Marcellino (2010) 
afirma que esse conteúdo deve ser multidisciplinar e também ministrado por profissionais de diferentes áreas do conhecimento.

Isayama (2010) destaca que em relação a essa formação profissional no lazer, o processo deve ser contínuo, incentivado e alimentado com cursos de diferentes naturezas (técnicos, de aperfeiçoamento, de especialização, de mestrado e de doutorado), em eventos técnicos e científicos e que isso faça parte do cotidiano desses profissionais.

Bandeira e Ribeiro (2015) nos trazem em seu estudo que devido à sua especificidade, a capacitação do profissional de aventura precisa ser prática e no ambiente de atuação, o que os cursos de ensino superior, seja em Lazer, Turismo ou Educação Física, ainda não podem oferecer. Não basta apenas incorporar os conteúdos da aventura nos currículos do ensino superior, deve-se valorizar o conhecimento não formal dos agentes sociais locais e também melhorar a qualidade dos cursos técnicos intensivos oferecidos tanto por entidades esportivas quanto por seus empreendedores, em uma formação transdisciplinar que preferencialmente deveria combinar estas diversas fontes de informação e experiência.

As pessoas que trabalham com atividades de aventura muitas vezes não conseguem dividir trabalho e lazer em seu cotidiano, já que trabalham para o lazer de outras pessoas. Esta afirmação, segundo nossa pesquisa, corrobora o que diz Parker (1978) ao afirmar que nas sociedades primitivas não havia períodos de lazer definidos, algumas atividades econômicas, como a caça ou a ida ao mercado, tinham características recreativas assim como o canto ou a narração de histórias. Desconheciase um tempo específico para a recreação e o divertimento. 
A formação dos profissionais de atividades de aventura não regulamentadas por federações ou confederações não é satisfatória quanto ao conteúdo técnico específico e à formação no âmbito do lazer, tanto os profissionais de atividades regulamentadas como os das não regulamentadas não têm conhecimento suficiente para atuar como animadores socioculturais, ou seja, como profissionais do lazer.

Em relação a isso Isayama (2010) salienta que é necessário um esforço sistemático em relação a formação continuada com produção de conhecimento que possa gerar processos de atuação profissional e que essa formação esteja preocupada com conteúdos e finalidades e seja mais acessível aos profissionais.

\section{Considerações Finais}

Em sua maioria, os profissionais de atividades de aventura da cidade de SocorroSP, não tem uma formação específica, seja em cursos técnicos ou de nível superior. Sua formação é pautada na transmissão do conhecimento entre colegas mais experientes e alguns poucos cursos de formação específica.

Em relação a isso, consideramos ser muito importante uma formação acadêmica em áreas que abordem conteúdos específicos para trabalhar com atividades de aventura no âmbito do lazer, embora ela não seja valorizada pelos próprios profissionais investigados. Grande parte dos entrevistados, possuem formação em nível superior e devem ser incentivados inclusive a participarem de congressos, eventos e cursos de pósgraduação na área das atividades e esportes de aventura.

Consideramos que cursos específicos devem ser elaborados por uma equipe multidisciplinar de profissionais, contendo o conhecimento teórico e prático que prepare, de forma ampla, o futuro profissional que vai atuar em atividades de aventura. 
Devem-se levar em conta conhecimentos de educação ao ar livre, as normas técnicas para o turismo de aventura e também a experiência nas atividades já regulamentadas. Nesse grupo, é imprescindível a participação de representantes das associações locais que, em sua maioria, são pessoas mais experientes e que podem contribuir, e muito, para a vivência na modalidade. Tais cursos devem ser financiados por programas públicos de capacitação profissional ou pelas próprias associações e federações, o que facilitaria o acesso dos envolvidos com um baixo custo de participação.

O profissional experiente deve participar da formação superior ou especifica, pois grande parte dos sujeitos do presente estudo, sabem que trabalham com lazer, mas não sabem realmente como trabalhar este lazer e quais os conteúdos que devem ser trabalhados com os seus clientes durante toda a atividade. Dessa forma, os clientes não devem apenas vivenciar a execução de uma atividade, mas adquirirem uma aprendizagem durante a prática.

Não pretendemos exaurir o assunto, nem mesmo apresentar soluções para todas as inquietações levantadas. Porém, buscamos apresentar algumas reflexões, respostas e investigações acerca do que foi proposto. Sabemos que é necessária a continuidade deste estudo em outros projetos para ampliar o enfoque aqui apresentado.

\section{REFERÊNCIAS}

ABETA. Associação Brasileira das Empresas de Ecoturismo e Turismo de Aventura, 2005. Disponível em: www.abeta.tur.br . Acesso em: 06 dez. 2012.

AURICCHIO, J. R. A escalada na educação física escolar: orientação adequada para a prática segura. Revista Digital EFDeportes, Buenos Aires, a. 14, n. 139, dez. 2009. Disponível em: http://www.efdeportes.com/efd139/escalada-na-educacao-fisicaescolar.htm . Acesso em: 25 abr. 2012.

. Técnicas verticais: conceituação, utilizações e segurança. In: SCHWARTZ, G.

M. et al. Tecnologias e atividades de aventura. São Paulo: Lexia, 2012. 
. Segurança e gestão de risco nas atividades de aventura. EFDeportes.com,

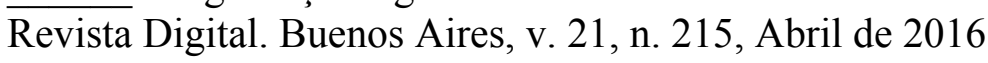

BANDEIRA, M. M; RIBEIRO, O. C. F. Sobre os profissionais da aventura: problemas da atuação na interface esporte e turismo. Licere, Belo Horizonte, v.18, n.3, set/2015

BETRÁN, J. O. Rumo a um novo conceito de ócio ativo e turismo na Espanha: as atividades físicas de aventura na natureza. In: MARINHO, A.; BRUHNS, H. T. (Org.). Turismo, lazer e natureza. São Paulo: Manole, 2003. p

BRASIL. Ministério do Turismo. Regulamentação, normatização e certificação em turismo de aventura. Relatório diagnóstico. Brasília: Ministério do Turismo, 2005.

BUCKLEY, R; UVINHA, R. R. Turismo de aventura: gestão e atuação profissional. São Paulo: Elsevier, 2011.

CORREA, E. A. Formação do profissional de educação física no contexto das atividades físicas de aventura na natureza. Unesp - Rio Claro: [s.n.], 2008

DIAS, C. A. G. Para uma história do lazer na natureza. In: DIAS, C. A. G.; ALVES JUNIOR, E. D. (Org.). Em busca da aventura: múltiplos olhares sobre esporte, lazer e natureza. Niterói: Eduff, 2009.

DUMAZEDIER, J. Lazer e cultura popular. 3. ed. São Paulo: Perspectiva / SESC, 2001 .

FERREIRA, A. B. de H. Minidicionário da língua portuguesa. 2. ed. Rio de Janeiro: Nova Fronteira, 1989.

FREIRE, M. Diálogo entre a educação e a natureza In: SCHWARTZ, G. M. (Org.). Aventuras na natureza: consolidando significados. Jundiaí: Fontoura, 2006.

ISAYAMA, H. F. (Org.). Lazer em estudo: currículo e formação profissional. Campinas: Papirus, 2010.

KUNREUTHER, F. T; FERRAZ, O. L. Educação ao ar livre pela aventura: o aprendizado de valores morais em expedições à natureza. Educação e Pesquisa, São Paulo, v. 38, n. 2, p. 437-452, abr./jun. 2012.

MAIA, L. F. S. A formação de técnico em lazer e suas possibilidades de atuação e intervenção em políticas públicas. In: MARCELLINO, N. C. (Org.). Formação e desenvolvimento de pessoal em lazer e esporte. Campinas: Papirus, 2003

MARCELLINO, N. C. Lazer e humanização. Campinas: Papirus, 1983.

Lazer e Educação. 3. ed. Campinas: Papirus,1995.

. O lazer na atualidade brasileira: perspectivas na formação/atuação profissional.

Licere, Belo Horizonte, v. 3, n. 1, p. 125-133, 2000. 
. (Org.). Formação e desenvolvimento de pessoal em lazer e esporte para atuação em políticas públicas. Campinas: Papirus, 2003.

. Lazer e educação. 11. ed. Campinas: Papirus, 2002.

. Políticas públicas de lazer. In: MARCELLINO, N. C. et al. Políticas públicas de lazer: formação e desenvolvimento de pessoal. Curitiba: Opus, 2007.

- Contribuições de autores clássicos, modernos e contemporâneos para os estudos do lazer. Licere, Belo Horizonte, v. 3, n. 4, dez. 2010.

MARINHO, A. Atividades na natureza, lazer e educação ambiental: refletindo sobre algumas possibilidades. Motrivivência, Florianópolis: v. 16, n. 22, p. 47-69, jun. 2004.

; SCHWARTZ, G. M. Atividades de aventura como conteúdo da educação física: reflexões sobre seu valor educativo. Lecturas Educación Física y Deportes, Buenos Aires, n. 88, 2005.

; DE GÁSPARI, J. C. Turismo de aventura e educação: desafios e conquistas de espaços. Turismo: visão e ação. Santa Catarina: Universidade do Vale do Itajaí, v.5, n.1, p.29-38, jan-abr, 2003.

MELLO, V. A. A formação cultural do animador cultural: antigas reflexões, persistências e continuidades. In. ISAYAMA, H. F. (Org.). Lazer em estudo: currículo e formação profissional. Campinas: Papirus, 2010.

MOESCH, M. Turismo e lazer: conteúdos de uma única questão. In: MARCELLINO, N. C. (Org.). Formação e desenvolvimento de pessoal em lazer e esporte: para atuação em políticas públicas. Campinas: Papirus, 2003.

NEIRA, M. G.; UVINHA, R. R. Cultura corporal: diálogos entre educação física e lazer. Petrópolis: Vozes, 2009.

PARKER, S. A sociologia do lazer. Rio de Janeiro: Zahar, 1978.

PIMENTEL, G. G. A. Esportes na natureza e atividades de aventura: uma terminologia aporética. Rev. Bras. Ciênc. Esporte, Florianópolis, v. 35, n. 3, p. 687-700, jul. /set. 2013

PINA, L. W. Multiplicidade de profissionais e funções. In: MARCELLINO, N. C. (Org.). Lazer: formação e atuação profissional. 9. ed. Campinas: Papirus, 1995.

SEVERINO, A. J. Metodologia do trabalho científico. 23. ed. São Paulo: Cortez, 2010.

SPINK, M.J; SPINK, S.P.P. Aventura esportiva na modernidade tardia. In. DIAS, C.A.G; ALVES JUNIOR, E.D. Em busca da Aventura: Múltiplos olhares sobre esporte, lazer e natureza. Niterói: EdUFF, 2009 
STOPPA, E. A; ISAYAMA, H. F; UVINHA, R. R; SILVA, L. F; DELGADO, M; CAPI, A. H. C; STEIDLE, A. A; SILVA, D. A. M; COUTO. H. R. F; TREVISAN, K; MARCELLINO, N. C. A produção do conhecimento na área do lazer: uma análise sobre as temáticas formação e atuação profissional nos anais do Enarel de 1997 a 2006. Licere, Belo Horizonte, v.13, n.2, jun/2010

TEREZANI, D. R. Propostas de animação relacionadas a esportes radicais. In: MARCELLINO, N. C. (Org.). Lazer e recreação: repertório de atividades por ambientes. Campinas: Papirus, 2010. v. II.

UVINHA, R. R. Juventude, lazer e esportes radicais. São Paulo: Manole, 2001.

UVINHA, R. R. (Org.). Turismo de aventura: reflexões e tendências. São Paulo: Aleph, 2005a. (Série Turismo).

. Viagens de aventura: o turismo e os esportes radicais. In. DIAS, C.A.G; ALVES JUNIOR, E.D. Em busca da Aventura: Múltiplos olhares sobre esporte, lazer e natureza. Niterói: EdUFF, 2009.

WERNECK, C. L. G. A formação profissional no lazer em nossa moderna sociedade: repensando os limites, os horizontes e os desafios para a área. Licere, Belo Horizonte, v. 1, n. 1, p. $47-65$, set. 1998 .

Lazer, trabalho e educação: relações históricas e questões contemporâneas. Belo Horizonte: UFMG/CELAR, 2000.

ZINK, R; BOYES, M. The nature and scope of outdoor education in New Zealand schools. Australian Journal of Outdoor Education, Australia, v. 10, n. 1, p. 11-21, 2006.

\section{Endereço do Autor:}

José Ricardo Auricchio

Rua José Martins Borges, 56 - Tremembé

São Paulo - SP - 02.348-080

Endereço Eletrônico: prof.auricchio@hotmail.com 